\title{
DIREITO CONSTITUCIONAL TRANSNACIONAL: OBSERVAÇÕES SOBRE OS ATRATORES SISTÊMICOS ENTRE DIREITO, ECONOMIA E POLÍTICA NA ARTICULAÇÃO TRANSNACIONAL PARA A APURAÇÃO DA LAVAGEM DE DINHEIRO
}

\begin{tabular}{l|l}
\hline RECEBIDO EM: & 9.4 .2020 \\
\hline APROVADO EM: & $\mathbf{1 6 . 4 . 2 0 2 0}$ \\
\hline
\end{tabular}

* Doutor pela École des Hautes études en Sciences Sociales (Ehess), com estudos de pós-doutorado em Sociologia do Direito pela Università degli Studi di Lecce na Itália. Professor titular da Universidade do Vale do Rio dos Sinos (mestrado e doutorado) e do Programa de Pós-Graduação em Direito(PPGD) da Universidade Regional Integrada do Alto Uruguai (URI). Bolsista de Produtividade em Pesquisa do Conselho Nacional de Desenvolvimento Científico e Tecnológico (CNPq) - Nível 1D. Membro do projeto de pesquisa “Observação sistêmica da violência como sistema organizacional na criminalidade em rede e seus reflexos no mercado: análise comparativa entre a operação Mãos Limpas e a operação Lava Jato” financiado pelo CNPq. E-mail: leonel@unisinos.br

* Doutorando em Direito Público do Programa de Pós-Graduação em Direito da Universidade do Vale do Rio dos Sinos (Unisinos) e mestre em Direito Público pela mesma instituição. Bolsista da Coordenação de Aperfeiçoamento de Pessoal de Nível Superior (Capes). E-mail: bernardoleandro@me.com 
- RESUMO: O presente trabalho tem como objetivo evidenciar a insuficiência do modelo tradicional de observação do constitucionalismo e demonstrar como uma observação da Constituição a partir da Teoria dos Sistemas Sociais, metodologia adotada na pesquisa, pode auxiliar nas articulações sistêmicas para a solução de problemas constitucionais globais. Para tal, faz-se uma construção histórica do constitucionalismo, passando por suas principais influências como fenômeno conectado à Teoria Geral do Estado, e, posteriormente, demonstra-se o impacto da globalização sobre essa perspectiva teórica, evidenciando suas insuficiências. Como hipótese para a resposta ao problema, no âmbito da Sociologia das Constituições, utiliza-se da concepção teórica de atratores, proposta por Teubner, para a solução de bloqueios da comunicação entre sistemas sociais. Por meio de um caso bem-sucedido de articulação sistêmica para resolver um caso de natureza global, apresenta-se a articulação transnacional para o combate à lavagem de dinheiro, com ênfase nos seus desdobramentos no Brasil. PALAVRAS-ChAVE: Sociologia das Constituições; atratores; lavagem de dinheiro.

\section{TRANSNATIONAL CONSTITUTIONAL LAW: OBSERVATIONS ABOUT THE SYSTEMIC ATTRACTORS BETWEEN LAW, ECONOMY AND POLITICS IN THE TRANSNATIONAL ARTICULATION FOR THE INVESTIGATION OF MONEY LAUNDERING}

- AвStRAct: The present article aims to show the insufficiency of the traditional model of observation of constitutionalism and to demonstrate how an observation of the Constitution from the Theory of Social Systems, methodology adopted in the research, can help in the systemic articulations to solve global constitutional problems. With that propose, does a historical construction of constitutionalism, passing through its main influences as a phenomenon connected to the rule of law, and, later, the impact of globalization on this theoretical perspective is demonstrated, highlighting its insufficiencies. As a hypothesis to answer the problem, within the scope of the Sociology of the Constitutions, the theoretical conception of attractors, proposed by Teubner, is used to solve communication blocks between social systems. Considered as a successful case of systemic articulation to solve a case of 
a global nature, the transnational articulation against the money laundering crime is presented, emphasizing his consequences in Brazil, as an example.

- KEYWords: Sociology of Constitutions; attraction; money laundry.

\section{Introdução}

Ao menos desde o avanço do fenômeno da globalização econômica no final do século XX, o direito constitucional tem se deparado com o necessário enfrentamento de problemas de natureza global. Nesse cenário, a tradicional concepção de Constituição, como documento único vinculado a determinado Estado, apresenta limitações, na medida em que os desafios atuais perpassam as fronteiras dos países.

Partindo-se dessa problemática, buscar-se-á, no presente artigo, traçar um panorama histórico do constitucionalismo, destacando suas origens conectadas à Teoria Geral do Estado, com evidência nas construções teóricas de Carré de Malberg (1948) na França e de Georg Jellinek (2000) na Alemanha.

Na sequência, englobando o mesmo item deste trabalho, demonstrar-se-á o modo como o fenômeno da globalização, com destaque para a econômica, avançou no final do século XX, evidenciando o deslocamento de diversas questões jurídicas e políticas para a esfera global. A partir dessa problemática, será evidenciada, de plano, a insuficiência da tradicional concepção de Constituição para o enfrentamento dessas questões.

Em um item subsequente, apresentar-se-ão os impulsos da Sociologia das Constituições, ramo de estudos que propõe alternativas para adaptar o panorama do direito constitucional aos problemas da globalização. Nessa parte, serão apresentadas as perspectivas de Thornhill (2011) para observar o fenômeno constitucional por meio do funcionalismo-histórico e de Teubner (2016a) no âmbito da fragmentação e do pluralismo jurídico.

Em destaque, demonstrar-se-á a observação de Teubner sobre o bloqueio da comunicação sistêmica sobre determinados fatos. Nessa perspectiva, em análise do autor sobre a obra literária de Gabriel García Márquez (2011), Crônica de uma morte anunciada, far-se-á uma descrição das possibilidades de solução das limitações comunicativas a partir da ideia de atratores.

A partir dessas questões, da dificuldade, por um lado, de tratar questões de natureza global por meio da perspectiva tradicional de Constituição, e das possibilidades 
de bloqueio comunicativo, por outro, nas observações de diferentes sistemas sociais sobre o mesmo problema, a hipótese do presente trabalho, a ser apresentada no quarto item do artigo, é a possibilidade de observar a articulação transnacional para o combate ao delito de lavagem de dinheiro como uma solução sistêmica trabalhada a partir da lógica de atratores comunicativos entre os sistemas da economia, do direito e da política em nível global, proposta apresentada por Teubner (2005b) para solucionar o bloqueio da comunicação em ambientes de pluralismo jurídico.

Nesse sentido, retomando pressupostos da Teoria dos Sistemas Sociais apresentados no terceiro item, far-se-á uma demonstração da evolução no tratamento do delito de lavagem de dinheiro, evidenciando, nessa proposta, as articulações sistêmicas para a solução de um problema alçado globalmente. No referido tópico, demonstrar-se-á o modo como o Brasil participa dessa articulação, verificando como as questões alteradas podem ser observadas ao longo da Operação Lava Jato.

Em aportes finais, com o intuito de realizar um balanço entre as análises referidas ao longo do artigo, buscar-se-á demonstrar como a referida articulação em nível global provocou alterações no âmbito do direito constitucional, sendo pensada e desenvolvida a partir da ideia de sistemas sociais alçados ao patamar da sociedade mundial. Nesse sentido, será evidenciado o patamar transnacional das constituições (acoplamentos estruturais em perspectiva sistêmica) na atualidade, tendo a apuração do delito de lavagem de dinheiro como um dos exemplos de problemas globais solucionados a partir da concepção de atratores entre os sistemas da economia, do direito e da política.

Como metodologia, será utilizada a Teoria dos Sistemas Sociais, perpassando a teoria de base das propostas de observação elencadas no decorrer do artigo, com destaque para as concepções de atratores e do ramo de estudos da Sociologia das Constituições. Como método de procedimento, será utilizada a técnica de pesquisa de documentação indireta, com revisão de bibliografia nacional e estrangeira.

\section{O constitucionalismo: perspectiva tradicional e suas limitações na globalização}

Na clássica distinção traçada entre direito privado e direito público, Malberg (1948, p. 21) define o direito constitucional como o ramo do direito aplicável às relações sociais em que o Estado seja parte. A Constituição, nessa perspectiva, trataria das regras e instituições que formam a estrutura estatal. 
Em tal ponto de análise, o Estado e seus respectivos elementos constitutivos são imprescindíveis para a concepção de Constituição elaborada nesse contexto. $\mathrm{O}$ documento constitucional único é vinculado a uma comunidade estatal, caracterizada por seu território, dentro do qual, nos limites da concepção moderna de soberania, aplicar-se-ia o poder autorizado e ao mesmo tempo limitado pela Constituição. Estado e Constituição, portanto, estão intrinsicamente imbricados nesse ponto de vista.

Na Alemanha, país de extrema importância na construção do direito constitucional, Jellinek (2000) reconhece a origem da perspectiva anteriormente citada no pensamento de Carré de Malberg na França. É interessante notar que Jellinek constrói uma verdadeira Teoria Geral do Estado, estando a Constituição e o próprio direito constitucional imbricados nessa proposta.

Iniciando pela distinção entre direito privado e público, ou seja, ramo do direito aplicável nas relações com o Estado, Jellinek (2000, p. 274) afirma que a Constituição serve para regular o exercício de poder estatal (imperium) dentro de determinado território, em relação aos indivíduos a ele submetidos.

Ademais, é perceptível o surgimento dessa construção de observação do direito constitucional na França, assim como afirma Jellinek sobre os estudos de Carré de Malberg, na própria Declaração dos Direitos do Homem e do Cidadão. Sobre o ponto de análise desse documento histórico, no artigo 16 da Declaração dos Direitos do Homem e do Cidadão (2010), consta o seguinte: "Qualquer sociedade em que não esteja assegurada a garantia dos direitos, nem estabelecida a separação dos poderes não tem Constituição”.

Portanto, no surgimento de observação do direito constitucional a partir dessa perspectiva, baseando-se na afirmação de Jellinek sobre a formação de tal corrente de pensamento na França, por meio dos estudos de Carré de Malberg, a análise teórica é feita por meio da observação e descrição de um documento constitucional. Restando assegurada a garantia de direitos e estabelecida a separação de poderes, pode-se falar de Constituição.

Diversos debates sucederam essa origem de autores que vincularam o fenômeno constitucional à estrutura estatal, com seus elementos constitutivos, e à observação de um documento único. Todavia, o fato é que tais estudos mantiveram a concepção unitária e estatal de Constituição.

Ao longo do século XX, as relevantes discussões travadas entre Kelsen (2003, p. 131) e Schmitt (2007, p. 139) apresentaram argumentos acerca da guarda da Consti- 
tuição, a ser realizada por um tribunal específico ou pelo próprio presidente do Reich, entre diversos outros elementos de discussão. Todavia, apesar dessas discordâncias, a perspectiva de direito constitucional apresentada ainda permaneceu vinculada a uma Constituição conectada a determinado território.

De maneira dominante, somando-se à perspectiva tradicional do direito constitucional, principalmente nas construções de Malberg (1948) e Jellinek (2000, p. 374), a concepção de sanção kelseniana passou a influenciar fortemente os estudos em direito constitucional do século XX, vinculando a Constituição aos elementos constitutivos do Estado.

Ocorre que, no final do século XX, o impulso do fenômeno da globalização mudou drasticamente o contexto de observação das relações entre direito e política. A título de ilustração, pode-se marcar a queda do Muro de Berlim como um ponto importante para o processo de globalização da economia. Para além das relações econômicas, outras atividades passaram para a escala global.

Todavia, há elementos que, apesar de todas as discussões ocorridas ao longo do século XX, mantiveram-se íntegros na Teoria Constitucional. Pode-se apontar, portanto, que o direito constitucional permaneceu dependente de uma Constituição como documento único, vinculada ao território de determinado Estado, elencando as prerrogativas e limitações de aplicar do poder estatal.

No âmbito do direito constitucional, as observações foram construídas com base em uma relação intrínseca entre Estado e Constituição, em uma vinculação estrita do direito e da limitação de relações de poder exercidas dentro de determinado território. Essas circunstâncias contribuíram para detectar a dificuldade de globalização do direito constitucional, ao passo que os problemas envolvendo direito e política estão alçados à escala global.

Por um lado, observa-se a fácil globalização de áreas como a própria economia, cujo sistema encontra-se alçado em escala global. Por outro lado, percebe-se a dificuldade que a política e o direito têm para a solução de problemas de natureza global (TEUBNER, 2003, p. 13).

No âmbito da criminalidade transnacional, a título de exemplo, os casos envolvendo lavagem de dinheiro e terrorismo serão totalmente ineficientes se as tentativas de apuração forem realizadas tão somente no interior de determinado Estado, como possibilita a tradicional observação do constitucionalismo, descrita anteriormente. So- 
bre esse aspecto, há tempos Neves (2009, p. 34) evidencia a ineficácia das decisões dos tribunais de cada país, decidindo isoladamente, nesses casos.

Questão ainda mais global é observada nos conflitos envolvendo o meio ambiente. De fato, a poluição ou a escala dos desastres ambientais não pode ser limitada ao âmbito de determinado Estado nacional ou resolvida nele. Não há como limitar a violação ao meio ambiente a um país específico, na medida em que o planeta como um todo é atingido.

Partindo-se dessa problemática, inicialmente se constata que o direito constitucional passa a encarar desafios inerentes ao processo de globalização, ao mesmo tempo que possui limitações a partir de sua tradicional perspectiva de observação. O delito de lavagem de dinheiro é um desses exemplos.

Assim, a partir da afirmação de que a sociedade, com o avanço do processo de globalização, apresenta desafios de natureza global ao direito, faz-se necessária uma construção teórica apta ao enfrentamento desses problemas, uma vez que a vinculação da ideia de Constituição à Teoria Geral do Estado parece incapaz de responder a essas questões (TEUBNER, 2005b, p. 73).

Inicialmente, cabe destacar as tentativas de adaptação de alguns autores oriundos da matriz normativista de observação do direito constitucional. Nesse sentido, um dos autores mais influentes da matriz analítica, fiel seguidor das concepções de Kelsen, destacou a necessidade de observações sociológico-sistêmicas sobre o fenômeno jurídico, adaptando, inclusive, as propostas kelsenianas sobre sanção.

No âmbito do direito constitucional, destacam-se os dois diferentes momentos de Canotilho. Inicialmente defensor da proposta de uma Constituição dirigente, cujo texto deveria guiar a atuação dos agentes estatais na concretização de direitos, visão tipicamente normativista, Canotilho (1982), a partir da percepção do movimento de transnacionalidade jurídica ocorrido entre os países da Europa, altera sobremaneira seu pensamento sobre o fenômeno constitucional.

Por meio dessa concepção, Canotilho (2008) passa a sustentar o conceito de interconstitucionalidade, tendo a Teoria dos Sistemas Sociais de Luhmann (2016) como fundamento teórico.

Ackerman (2007, p. 89), por sua vez, no contexto do direito constitucional norte-americano, tradicionalmente conhecido por seu fechamento em relação às questões globais, passou a defender a necessária abertura dos Estados Unidos para o enfrentamento de questões atinentes à globalização. Para isso, segundo Ackerman(2007), faz-se 
necessário o abandono de uma concepção provincialista de Constituição, defendendo-se uma necessária abertura para os atuais problemas do constitucionalismo.

Nesse sentido, faz-se importante observar que, mesmo os Estados Unidos não fazendo parte da União Europeia, as decisões tomadas no contexto europeu, mormente em casos de natureza global, acabam influenciando as decisões de diferentes tribunais norte-americanos. Em síntese, observa-se cada vez mais a inevitável globalização do direito constitucional, constatada não apenas por autores que vivem no ambiente na União Europeia, mas também por autores de fora, a exemplo das afirmações de Tushnet (2009).

Avançando nessas questões, como proposta teórica para o enfrentamento dessas problemáticas, surgiu o ramo de estudos denominado de Sociologia das Constituições. Esse tipo de observação jurídica retoma alguns pontos de divergência da teoria sociológica de Ehrlich (1962) e de sua crítica a Kelsen, conforme apontado anteriormente. Nesse ponto, destacam-se as influências dessa corrente de pensamento nos estudos sociológicos norte-americanos, com evidência nas propostas de Nonet e Selznick (2010).

Ademais, evidencia-se a influência das concepções sobre o direito vivo na teoria de Sciulli (1988), autor que utilizou pela primeira vez a expressão constitucionalismo social, posteriormente retomada por Teubner (2016a). Todavia, a grande base teórica para essa proposta é derivada da Teoria dos Sistemas Sociais de Luhmann (2016).

Dessa teoria de base partem os trabalhos de Febbrajo (2016), Neves (2009), Teubner (2016b) e Thornhill (2016), propondo diferentes observações e soluções para alçar a Constituição ao plano global. Trata-se de concepções que observam o constitucionalismo a partir da Teoria dos Sistemas Sociais, tendo como base a comunicação sistêmica desenvolvida no âmbito da sociedade mundial, conforme se demonstrará na próxima seção.

\section{A Sociologia das Constituições e seus impulsos}

No âmbito da Sociologia das Constituições, Thornhill (2011, p. 32-38) propõe uma metodologia denominada de funcionalismo histórico para observar a evolução do fenômeno constitucional ao longo da formação do Estado, pois houve um momento em que o sistema da política passou a utilizar fundamentações jurídicas para suas decisões. A partir desse momento, formou-se o que se concebe por Constituição. Para Thornhill 
(2011), essa utilização teve início no final do século XII e no começo do XIII na Europa, a partir da utilização de princípios do direito romano, na construção do que viria a ser o direito público.

Nesse sentido, portanto, é possível observar o modo como se forma o acoplamento estrutural entre os sistemas do direito e da política. A Constituição é o elo que medeia essa relação (ROCHA; COSTA, 2018, p. 45). Há, em síntese, duas organizações que estão vinculadas em suas decisões: os Estados e os tribunais.

Os sistemas da política e do direito, em que pese a possibilidade de aplicar seus códigos binários para observar suas distinções globalmente, possuem suas organizações (Estados e tribunais) vinculadas aos âmbitos internos dos diferentes países. Por sua vez, o sistema da economia possui organizações que atuam facilmente na comunicação global, como a Organização Mundial do Comércio e os diferentes bancos atuantes em escala multinacional pelo menos.

A Teoria dos Sistemas sociais fornece um arcabouço teórico capaz de descrever o tipo de observação que diferentes atores possuem sobre o mesmo fato. Quando há um caso de natureza global, é possível fazer uma análise estritamente econômica sobre a questão, vinculando o sentido dessa comunicação a partir do código binário lucro/não lucro. Essa possibilidade é recorrente entre os agentes do sistema da economia, afinal, há uma tomada de decisão baseada na lucratividade.

Para resolver problemas oriundos desse tipo de observação, os operadores do sistema do direito observam o mesmo fato a partir do código binário direito/não direito e realizam comunicações tematizadas como decisões por meio dos tribunais. Ao mesmo tempo, o sistema da política, ao observar o fato problemático, toma uma decisão que pretende ser coletivamente vinculante. Todavia, como já afirmado, as organizações desses sistemas estão conectadas às estruturas internas de cada país. De certo modo, há uma limitação no alcance de questões globais:

- É possível articular conexões sistêmicas para resolver esse bloqueio na comunicação?

- De algum modo, as comunicações dos sistemas do direito e da política podem servir para o desenvolvimento do sistema da economia?

Teubner (2016b), nesse sentido, tem destacado a formação de constituições parciais, de sistemas autônomos formados no âmbito da economia, por exemplo, mas de 
vários outros sistemas também. Em síntese, os operadores do sistema da economia seguem um âmbito de normatividade que não está mais ligado ao sistema do direito nos moldes da teoria de Luhmann. Teubner (2016b), com inspiração na concepção de norma sem sanção de Kelsen, denomina isso fragmentos constitucionais.

Em síntese, Teubner (2016b) demonstra a tendência de observações baseadas estritamente em perspectivas de um sistema social forte e globalizado, a exemplo da economia, dispensando os operadores a ele pertencentes e as possíveis observações jurídicas sobre o fato. Ademais, há inclusive construções jurídicas próprias desses sistemas, que guiam o atuar de seus agentes.

Contudo, de fato, essa questão é exclusiva do sistema da economia ou pode ser relacionada com a observação social de fatos que, em termos do sistema do direito, possuem sentido de antijuridicidade, mas que podem ser observados de outro modo? Quando se questiona sobre o direito, não há a exclusão da ilicitude baseada em outros meios de comunicação?

Sobre essa questão, Teubner (2005b), em escritos que evidenciam a existência do pluralismo jurídico na sociedade, retoma, na literatura colombiana, o clássico Crônica de uma morte anunciada, de Gabriel García Márquez. Ao descrever essa grande obra literária, Teubner (2005b) demonstra como, a partir de um fato de fácil caracterização jurídica de ilicitude, um homicídio, há uma tentativa de exclusão da comunicação por esse código por meio de observações estranhas ao sistema do direito, utilizando-se os moradores de um pequeno vilarejo na Colômbia de códigos como a honra e a moral para excluir a ilicitude do fato observado, chegando ao ponto de conceder uma absolvição em júri popular aos assassinos envolvidos.

Em síntese, como diversos outros casos apresentados na globalização a partir das estruturas do sistema da economia, esse é um caso em que há uma observação estrita a partir de determinados códigos, desconsiderando totalmente observações jurídicas sobre o fato.

Ao mesmo tempo que Teubner (2005b) demonstra esses bloqueios na comunicação, evidencia a existência de atratores, elementos que atraem a comunicação estrita de um sistema para a consideração de comunicações existentes em outros sistemas sociais. Em resumo, para tornar interessante a observação jurídica aos observados, é preciso, inicialmente, verificar os pressupostos por meio dos quais ele realiza tal observação. Posteriormente, buscam-se os pontos cegos/as falhas dessa observação. 
Nos casos de natureza global, sabendo-se das facilidades de globalização do sistema da economia, por um lado, e das dificuldades dos sistemas da política e do direito, por outro, no tratamento dessas questões, é possível articular a formação de atratores para resolver esses problemas? De algum modo, a observação jurídica, com a capacidade dos tribunais e as decisões políticas, com força dentro dos países, pode ser interessante para casos que parecem estritamente econômicos?

Sobre essa questão, tentar-se-á demonstrar como ocorreu a articulação para o combate à lavagem de dinheiro em escala global, em perspectivas simultaneamente vinculadas aos sistemas do direito, da política e da economia. Buscar-se-á demonstrar como a ideia de atratores pode servir para resolver esses supostos bloqueios sistêmicos, auxiliando na resolução de casos de natureza global.

\section{Atratores entre economia, direito e política na articulação transnacional para o combate à lavagem de dinheiro}

A partir da obra Crônica de uma morte anunciada, de Gabriel García Márquez, Teubner (2005b) demonstra como um pequeno vilarejo da Colômbia imuniza a observação jurídica de um fato com base em códigos secundários que efetivam um bloqueio na comunicação. Assim, diversos outros modos de observar, por meio de dispositivos como “o direito à honra”, afastam a leitura do ocorrido como um homicídio.

Nesse sentido, em vias de demonstrar a existência de um pluralismo jurídico na sociedade, Teubner (2005b, p. 24) evidencia como, a partir dessas leituras, o direito estatal tradicional, representado na história pelo direito penal, "peleja para permanecer em pé”. Por meio dessas constatações sociológicas, formam-se questionamentos acerca da capacidade do direito regulatório, oriundo do Estado, em regular os comportamentos sociais, na medida em que se formam esses bloqueios, representados, na literatura selecionada para o texto, pelo código da honra. Em perspectiva sistêmica, pode-se falar em hierarquia nas comunicações dos diferentes sistemas, opondo-se à simetria, modelo ideal em uma sociedade funcionalmente diferenciada.

Em síntese, na medida em que a Teoria dos Sistemas Sociais de Luhmann (2016) demonstra a possibilidade de pontos de observação divergentes sobre o mesmo fato, dependendo do sistema a partir do qual o sujeito vincula a sua comunicação, a eficácia 
social do direito é representada pela capacidade de dotar de sentido jurídico as diferentes situações sociais (TEUBNER, 2005b, p. 31). Trata-se da capacidade de observar determinado fato como homicídio, e não como legítima defesa da honra, citando a literatura de Gabriel García Márquez.

Trazendo essa discussão para questões atuais, Teubner (2016b) desenvolve sua tese para observação dos fragmentos constitucionais, espaços autônomos de regulação formados para além dos tradicionais sistemas do direito e da política, como descritos no item anterior, partindo de observações sistêmicas independentes. Um dos grandes exemplos - talvez o maior deles - é verificado no sistema da economia. De fato, como descreve Teubner (2016b), a Organização Mundial do Comércio, alçada ao patamar global, é dotada de certa autonomia que perpassa os tradicionais limites dos Estados.

Em síntese, é possível discutir muito sobre a onda de fragmentação constitucional, evidenciando a existência ou não de problemas a ela conectados e propondo modelos para a solução de colisões entre essas estruturas, como faz Teubner (2016b, p. 302), defendendo um diálogo sistêmico mediado pela sustentabilidade.

Todavia, neste momento, interessa verificar as hipóteses e que há um bloqueio da observação jurídica causado pelo código de outro sistema social, ou seja, há certa dificuldade na observação jurídica de certas questões. Tal perspectiva guiou por muito tempo a apuração do delito de lavagem de dinheiro.

Nessas observações, é possível verificar como o delito de lavagem de dinheiro evolui de um simples procedimento realizado no âmbito dos territórios nacionais para um processo que envolve necessariamente a remessa de valores ao exterior. Em tal ação, passa-se a verificar a dificuldade inicial dos países no mapeamento do dinheiro e na capacidade do direito penal nacional para lidar com esses crimes que transcendem os territórios dos países.

Tal dificuldade verificou-se inicialmente na observação estritamente econômica que determinados países possuíam acerca do dinheiro que chegava de outra nação, independentemente de sua origem. Em tese, tais valores seriam agregados à economia local. Nessa percepção, havia um bloqueio das observações jurídicas sobre esse dinheiro enviado, como dinheiro de origem ilícita ou com vistas à lavagem no país de destino.

Como destaca Teubner (2005b, p. 34), há uma substituição da regulação de comportamentos de atores sociais na perspectiva jurídica (norma-consciência da sançãodesvio normativo), pela interface de discursos autônomos que dominam a comunicação. Nesse sentido, quando as normas jurídicas são observadas a partir do sistema da 
economia, não são destacadas como válidas ou inválidas, mas como encargos econômicos a serem superados.

A partir de casos como esse, é possível verificar algum ponto fraco na observação estritamente econômica? Por meio dessa constatação, se houver, há possibilidades de articulações entre os sistemas da economia, do direito e da política para resolver um problema que simultaneamente interessa a todos esses âmbitos.

Para essa articulação na comunicação, Teubner (2005b, p. 38) utiliza o termo atratores. É interessante, nesse sentido, para que se faça uma observação jurídica sobre o problema, demonstrar o ponto fraco da comunicação econômica em questão, provocando, em linguagem sistêmica, uma irritação jurídica no sistema da economia.

No delito de lavagem de dinheiro em específico, vale lembrar que o sistema da economia, mais do que todos os outros, está alçado a um patamar global. Nesse sentido, a remessa constante de valores com origem ilícita de um país a outro, dinheiro não captável em termos de previsibilidade econômica, é capaz de criar uma instabilidade na economia global. Por sua vez, os valores oriundos de lavagem são ativos que não permanecem por muito tempo no país para o qual foram enviados. Esse dinheiro é lavado no exterior e retorna ao país de origem para ser utilizado nele. Portanto, também nesse ponto, há um prejuízo no âmbito de estabilidade da economia de cada Estado.

Ademais, outro fator que impulsionou a ênfase da dimensão econômica do crime de lavagem de dinheiro ocorreu na década de 1980, no contexto da "guerra às drogas”, com o trânsito descontrolado de dinheiro entre países a partir de atividades ilícitas, com destaque para os dólares que se deslocavam dos Estados Unidos para outros países em decorrência do tráfico internacional de drogas. Nessa perspectiva, foi editado, em 1988, o primeiro documento internacional sobre o tema, a Convenção da ONU contra o Tráfico Ilícito de Entorpecentes e Substâncias Psicotrópicas. Nessa convenção, houve a primeira menção ao delito de lavagem de dinheiro em nível internacional (MACHADO, 2010, p. 142).

Em suma, algumas constatações evidenciaram pontos fracos de observação estritamente econômica de cada país sobre o delito de lavagem de dinheiro. A partir dessa verificação, sabendo-se que, com essas demonstrações, as observações jurídicas sobre o dinheiro remetido ao exterior para ser lavado passam a ser economicamente interessantes, questiona-se sobre a possibilidade de articulação sistêmica para a solução desse problema. 
Para um panorama sobre essa articulação, destaca-se igualmente a atuação do sistema da política, com a presença de cada Estado, como organização sistêmica, podendo tomar decisões que sejam coletivamente vinculantes a seus cidadãos. Nesse ponto, sabendo-se de sua dificuldade, assim como o sistema do direito, no âmbito da globalização, surge a configuração transnacional para a apuração de crimes como a lavagem de dinheiro.

Sabendo-se das dificuldades iniciais, já destacadas nos itens anteriores, acerca das limitações do direito tradicional, vinculado ao Estado, para apuração de casos de natureza global, formou-se uma articulação, especificamente no âmbito da lavagem de dinheiro, que elegesse o direito nacional como instância de aplicação jurídica e o direito internacional como sua esfera de produção. Assim, a proposta foi restaurar a autoridade dos Estados e de seus tribunais nas decisões sobre crimes que ocorrem ou geram efeitos em mais de uma jurisdição e formar uma comunicação legislativa comum entre diferentes países sobre a questão (MACHADO, 2010, p. 131).

Em síntese, uma dificuldade inicial verificada foi a diferença de tratamento dos mesmos delitos em diferentes países. A partir dessa constatação, deu-se prioridade para a definição de crimes transnacionais por meio da negociação internacional. Definidas como recomendações, essas negociações passaram a integrar a legislação dos diferentes países envolvidos.

Um primeiro passo, caracterizando a ideia de atratores anteriormente exposta, foi demonstrar a dimensão econômico-financeira de diversas atividades ilícitas no âmbito global. A partir dessa ênfase, alguns mecanismos no direito internacional passaram a abarcar a definição de transnacionalidade de alguns delitos, a exemplo das convenções da Organização das Nações Unidas (ONU) sobre o tráfico ilícito de entorpecentes, o financiamento do terrorismo (1999) e o crime organizado transnacional. Ademais, destaca-se a Convenção Internacional da ONU sobre o crime organizado transnacional (2003).

Como afirmado, a partir de um atrator para o sistema da economia, houve uma reconfiguração de pressupostos limitadores dos sistemas do direito e da política, com o intuito de possibilitar observações sobre a ilicitude de determinados fatos que interessavam em termos de lucro aos agentes econômicos.

Por meio de articulação entre Estados (sistema da política), passou-se a definir juridicamente a criminalidade transnacional, alterando sobremaneira a estrutura interna do sistema do direito. Em síntese, para o tratamento de questões que cruzam fron- 
teiras, ocorrendo em mais de um Estado, é necessária a construção de canais de diálogo para a reconstrução dos fatos, envolvendo a troca de informação entre agentes, além da criação de normas comuns ou compatíveis, privilegiando sua aplicação nos tribunais nacionais (MACHADO, 2010, p. 142).

Importante passo para a superação das dificuldades iniciais foi a articulação realizada por meio do Financial Ask Task Force (Fatf). O Grupo de Ação Financeira Internacional surgiu como uma entidade intergovernamental no ano de 1989. A partir de encontros com representantes de diferentes Estados, são articuladas soluções comuns para problemas de natureza global, entre os quais se enquadra a lavagem de dinheiro. Com o intuito de aproximar a legislação dos países no que tange à apuração dos crimes destacados pelo grupo, há a edição de documentos em que constam recomendações para que os países adotem nas suas legislações sobre a matéria.

Atualmente, os documentos oficiais do grupo apontam 40 recomendações (FINANCIAL ACTION TASK FORCE, 2020), que surgiram em 1990 e foram revistas nos anos de 1998, 2001, 2003 e 2012. Participante ativo do Grupo de Ação Financeira Internacional, o Brasil seguiu integralmente as recomendações acerca do delito de lavagem de dinheiro, tendo editado sua primeira lei sobre o tema para se adequar aos propósitos do grupo. Com essa intenção, surgiu a Lei n. 9.613, de 3 de março de 1998 (BRASIL, 1998), que coincidiu com a criação do Conselho de Controle de Atividades Financeiras (Coaf) para atender à exigência da manutenção de um conselho apto a controlar as atividades financeiras no interior de cada país, recebendo e selecionando informações oriundas de outros Estados. Posteriormente, após a revisão das recomendações do grupo em 2012, foi promulgada a Lei n. 12.683, de 9 de julho de 2012 (BRASIL, 2012), adequando-se às transformações propostas pelo Grupo de Ação Financeira Internacional. Outra questão destacada em termos de legislação a ser utilizada em panorama global é a referência a decisões ou panoramas de um tribunal internacional permanente, a exemplo das decisões do Tribunal Penal Internacional, tendo o Estatuto de Roma como uma referência na manutenção das garantias processuais penais(MACHADO, 2010, p. 139).

Em síntese, as recomendações do Grupo de Ação Financeira Internacional possuem forte aplicação na legislação dos países participantes, contribuindo na construção de uma comunicação comum em termos de legislação dos países, permitindo a apuração dos delitos pelos tribunais nacionais. Nesse ponto, percebe-se claramente uma alteração no âmbito interno do sistema do direito, evidenciando a transnacionalidade produzida na produção internacional e na aplicação nacional das disposições jurídicas. 
Importante questão trazida pelas recomendações do Grupo de Ação Financeira Internacional é o destaque à concepção de governança, imprescindível para a apuração de problemas de natureza global. Diferenciando-se da perspectiva tradicional de governo, de monopólio do Estado para o tratamento de questões de interesse público, faz-se imprescindível, na governança, que atores públicos e privados atuem para a solução da problemática. A partir dessa lógica, utilizam-se sistemas de comunicação digital para o cruzamento de dados dos diferentes atores participantes na apuração. Quando há participação de unidades de inteligência financeira estrangeiras, utiliza-se o uma Rede de Segurança (Egmont Secure Web), alimentada por diferentes países simultaneamente.

Nesse sentido, seguindo as recomendações do Grupo de Ação Financeira Internacional, a legislação brasileira prevê a participação de agentes econômicos que a todo o momento alimentam o sistema de informações do Coaf. Assim, o Coaf recebe, processa, filtra e cruza as informações oriundas de agentes nacionais e estrangeiros, realizando atos que antecedem a atuação da polícia e do Ministério Público Federal.

É interessante observar, no âmbito da transnacionalidade do direito, que as trocas de informações realizadas entre os agentes anteriormente citados, nacionais e internacionais, públicos e privados, dispensam tratado ou acordo, diferenciando-se das tradicionais tratativas do direito internacional. Há, nesse sentido, verdadeiras negociações bilaterais do Coaf envolvendo documentos internacionais. Muitas das negociações envolvem os denominados "memorandos de entendimento" (memorandum of understanding - MoUs), considerados documentos de natureza política, que não estão sujeitos à aprovação ou ao conhecimento por parte do Congresso Nacional.

Em síntese, em análise sistêmica, é possível observar como essa articulação transnacional para apurar o delito de lavagem de dinheiro apresenta novos mecanismos de cooperação entre atores envolvidos em uma governança global. No Brasil, a Operação Lava Jato utiliza-se com frequência desses instrumentos colocados à disposição dos países (COSTA, 2018). Como destaca Teubner (2005b, p. 43), a partir dos desafios enfrentados no âmbito de uma sociedade plural, a ideia de atratores é fundamental para uma reconfiguração no sistema do direito.

É interessante notar que, assim como outros casos que servem para exemplificar essa questão, a lavagem de dinheiro é um dos problemas globais que o direito constitucional precisa enfrentar atualmente. Como já se demonstrou, é impossível tratar essas questões no interior de cada país, a partir de uma concepção tradicional de constitui- 
ção. Trata-se de um exemplo típico de transnacionalidade do direito. Portanto, nessa questão, ocorreu uma verdadeira modificação no sistema do direito, de modo que, a partir da demonstração de pontos fracos das análises estritamente econômicas anteriores, os próprios atores do sistema da economia passaram a fazer observações jurídicas sobre esses problemas, sem desconsiderarem, simultaneamente, a obtenção de lucro que essas atividades podem gerar.

Para impulsionar essa articulação, como demonstrado anteriormente, em momentos de bloqueio da comunicação jurídica, um dos primeiros passos é identificar o ponto fraco de observações estritas de um sistema social específico. No caso deste estudo, fez-se tal análise com base na observação econômica, evidenciando-se que os rumos da lavagem de dinheiro poderiam colocar em risco o sistema da economia global. A partir dessa questão, formou-se a articulação entre os sistemas da política, do direito e da economia, resultando em comunicações que apresentam eficácia social de observações recíprocas sobre a problemática da lavagem de dinheiro.

\section{Considerações finais}

Como se viu ao longo do artigo, a tradicional concepção de constitucionalismo surgiu vinculada à ideia de uma Constituição conectada a determinado Estado, nos limites de seus elementos constitutivos, com destaque para território, povo e soberania. Tal perspectiva é visível nos trabalhos precursores de Carré de Malberg (1948), na França, e Jellinek (2000), na Alemanha.

No século XX, ocorreram relevantes debates constitucionais entre importantes autores como Kelsen (2003) e Schmitt (2007). Em comum nesses autores, apesar de suas divergências, permaneceu a concepção de que a Constituição é representada por um documento único vinculado a determinado Estado. Demonstrou-se, de maneira semelhante, o modo como a concepção normativista de direito de Kelsen passou a influenciar o pensamento jurídico-constitucional do século passado.

Em oposição, evidenciou-se a maneira como o avanço do fenômeno da globalização, alçando os problemas constitucionais mundialmente, colocou a tradicional concepção de Constituição vinculada ao território de determinado Estado em nível de insuficiência para o enfrentamento dessas questões.

Avançando nessa questão, como alternativas teóricas para observação e enfrentamento dos problemas de natureza global colocados ao direito constitucional, fez-se 
uma acerca da Sociologia das Constituições, destacando-se as propostas teóricas de Thornhill (2011) e Teubner (2016b). Nessas propostas, deu-se destaque ao enfrentamento de bloqueios na comunicação jurídica em ambientes de pluralismo jurídico evidenciados por Teubner (2005b).

Partindo-se da concepção teórica de atratores da comunicação entre diferentes sistemas sociais, buscou-se apresentar respostas aos problemas elencados ao longo do artigo. Por um lado, evidenciou-se a insuficiência da tradicional concepção de constitucionalismo para o enfrentamento de questões de natureza global. Por outro lado, já no nível da Teoria dos Sistemas Sociais, demonstraram-se as possibilidades de bloqueios nas observações de um fato a partir da dinâmica de determinado sistema específico.

Como confirmação da hipótese, demonstrou-se, ao longo do trabalho, a partir do exemplo da lavagem de dinheiro, que o elemento transnacionalidade alterou as estruturas internas do sistema do direito, que passou a tratar, nessa questão, com a articulação (governança) simultânea de atores públicos e privados nacionais e internacionais para a apuração dos fatos delituosos. Ademais, destacou-se a criação de uma legislação comum entre os países envolvidos a partir das recomendações do Grupo de Ação Financeira Internacional, evidenciando a produção internacional de legislação sobre o tema, posteriormente internalizada pelos diferentes países, mas com possibilidades de aplicação pelos tribunais nacionais.

Nessa linha, em um panorama histórico, verificou-se a identificação de um ponto fraco na observação estritamente econômica que os países possuíam antes dessa necessária transformação para a apuração da lavagem de dinheiro. A partir dessa constatação, que serviu como um atrator para que a comunicação jurídica voltasse a ser relevante no sistema da economia nesse caso, observa-se o modo como a alteração de certos conceitos jurídicos é necessária quando há uma preocupação em relação a observações exteriores ao direito sobre o mesmo fato.

Sendo assim, em resposta às insuficiências da tradicional perspectiva de constitucionalismo para a solução de problemas de natureza global, os estudos em Sociologia das Constituições apresentam relevantes observações, aptas à constatação dos problemas a das alternativas no tocante aos casos alçados ao patamar da sociedade mundial.

Nesse quadro encontra-se a teoria de Teubner, evidenciando a formação de espaços de regulação autônoma nos diferentes sistemas sociais autopoiéticos. Sobre essa questão, em um ambiente de pluralismo jurídico, destacam-se casos em que há um ver- 
dadeiro bloqueio da observação jurídica sobre determinados fatos, constatações que podem apontar para a "morte anunciada” do modelo tradicional de direito regulatório.

Todavia, ao mesmo tempo, a proposta de atratores, da apresentação de elementos que vinculem simultaneamente comunicações de diferentes sistemas, pode servir de impulso para a retomada da eficácia social do direito. Esta reside na capacidade de reproduzir eventos sociais como acontecimentos jurídicos (TEUBNER, 2005b, p. 61).

A referida dificuldade e a solução por meio dos atratores ocorreram na evolução da apuração do delito de lavagem de dinheiro, como demonstrado ao longo do artigo. Inicialmente constatando os pontos fracos da análise estritamente econômica feita por países que recebiam valores oriundos de atividades ilícitas, evidenciando o prejuízo da economia global a partir desses atos, demonstrou-se historicamente a necessidade de retomar comunicações jurídicas sobre esses atos (que passariam a ser ilícitos) com o intuito de economicamente estabilizar o sistema da economia.

Por meio de referida atração na comunicação, articularam-se simultaneamente mecanismos dos sistemas da política, do direito e da economia. No sistema do direito, formou-se uma legislação comum entre diferentes países envolvidos na apuração transnacional da lavagem de dinheiro, alterações realizadas a partir de membros de diferentes Estados (atores do sistema da política), permitindo a aplicação dessa legislação pelos tribunais nacionais de cada país (organização que representa o centro do sistema do direito).

Relevante nessa articulação foi a utilização de uma verdadeira governança, reunindo atores públicos e privados na solução de um problema comum. Diariamente, atores de todos os sistemas envolvidos, de diferentes países, trocam informações por meio de sistemas de comunicação digital, reciprocamente alimentando as informações necessárias para a apuração da lavagem de dinheiro.

Em síntese, pode-se concluir que, a partir da percepção dos possíveis atratores entre os sistemas envolvidos na comunicação, o próprio sistema da economia, que antes observava isoladamente o fenômeno da transição de dinheiro não declarado entre países de maneira isolada, impulsionou o desenvolvimento das organizações e das comunicações dos sistemas da política e do direito globalmente. Para o último, o avanço transnacional da legislação por ele utilizada (papel do sistema da política) e a possibilidade de aplicá-la nacionalmente por meio da troca de informações provocaram uma verdadeira alteração estrutural em seus limites internos, capacitando-o para o enfrentamento de casos de natureza global. 
A dinâmica dos atratores, portanto, aqui exemplificada por meio do caso envolvendo a evolução da apuração do delito de lavagem de dinheiro, é de extrema importância para o enfrentamento de possíveis bloqueios na comunicação, que podem ser verificados em uma série de casos globais na atualidade.

No presente trabalho, mostrou-se como a apuração do delito de lavagem de dinheiro utilizou essa dinâmica, sendo bem-sucedida na retomada da eficácia social do direito, na possibilidade de atores de outros sistemas sociais realizarem observações jurídicas sobre um fato que possui natureza igualmente econômica. Tal exemplo pode ser uma saída para novas articulações, em problemas já colocados ao direito constitucional na globalização. Para essa articulação, é imprescindível a observação possibilitada pela Teoria dos Sistemas Sociais, principalmente no tocante à sua concepção de Constituição, alçando-se os sistemas envolvidos nessa relação (direito e política) ao patamar da sociedade mundial.

\section{REFERÊNCIAS}

ACKERMAN, B. A ascensão do constitucionalismo mundial. In:SOUZA NETO, C.P.; SARMENTO, D. (orgs.). A constituição do direito: fundamentos teóricos e aplicações específicas. Rio de Janeiro: Lumen Juris, 2007, p. 89-111.

BRASIL. Lei n. 9.613, de 3 de março de 1998. Dispõe sobre os crimes de "lavagem" ou ocultação de bens, direitos e valores; a prevenção da utilização do sistema financeiro para os ilícitos previstos nesta Lei; cria o Conselho de Controle de Atividades Financeiras - Coaf, e dá outras providências. Brasília, 1998. Disponivel em: http://www.planalto.gov.br/ccivil_03/Leis/19613.htm. Acesso em: 8 jun. 2018.

BRASIL. Lei n. 12.683, de 9 de julho de 2012. Altera a Lei n. 9.613, de 3 de março de 1998, para tornar mais eficiente a persecução penal dos crimes de lavagem de dinheiro. Brasilia, 2012. Disponível em: http://www.planalto.gov.br/ccivil_03/_Ato2011-2014/2012/Lei/L12683.htm. Acesso em: 9 jul. 2019.

CANOTILHO,J.J. G.Constituição dirigente e vinculação do legislador: contributo para a compreensão das normas constitucionais programáticas. Coimbra: Coimbra, 1982.

CANOTILHO, J. J. G. "Brancosos” e interconstitucionalidade: itinerários dos discursos sobre a historicidade constitucional. 2. ed. Coimbra: Almedina, 2008.

COSTA, B. L. C. A evolução do constitucionalismo transnacional nos tribunais: uma análise sociológico-sistêmica da operação Lava Jato. 2018. 114 f. Dissertação (Mestrado em Direito) - Universidade do Vale do Rio dos Sinos, São Leopoldo, 2018.

EHRLICH, E. Fundamental principles of the sociology of law. New York: Russel e Russel, 1962.

FEBBRAJO, A. Sociologia do constitucionalismo. Tradução Sandra Regina Martini. Curitiba: Juruá, 2016. 
FINANCIAL ACTION TASK FORCE (FATF). 40 recommendations. Disponível em: https://www. fatf-gafi.org/publications/fatfrecommendations/documents/the40recommendationspublishedoctober2004.html. Acesso em: 30 abr. 2020.

FRANCE. Déclaration des Droits de l'Homme et du Citoyen de 1789. Disponível em: https://www. legifrance.gouv.fr/Droit-francais/Constitution/Declaration-des-Droits-de-l-Homme-et-du-Citoyen-de-1789. Acesso em: 7 fev. 2020.

GARCÍA MÁRQUEZ, G. Crónica de una muerte anunciada. Buenos Aires: Debolsillo, 2011.

JELLINEK, G. Teoría general del estado. Granada: Comares, 2000.

KELSEN, H. Jurisdição constitucional. São Paulo: Martins Fontes, 2003.

LUHMANN, N. O direito da sociedade. São Paulo: Martins Fontes, 2016.

MACHADO, M. R. As estratégias de intervenção sobre crimes transnacionais e o sistema de justiça criminal brasileiro. In: NEVES, M. (org.). Transnacionalidade do direito: novas perspectivas dos conflitos entre ordens jurídicas. São Paulo: Quartier Latin, 2010.

MALBERG, R. C. de. Teoría general del estado. México: Fondo de Cultura Económica, 1948.

MINISTÉRIO PÚBLICO FEDERAL. Estatuto de Roma do Tribunal Penal Internacional. Disponível em: http://pfdc.pgr.mpf.mp.br/atuacao-e-conteudos-de-apoio/legislacao/ segurancapublica/estatuto_roma_tribunal_penal_internacional.pdf. Acesso em: 9 jul. 2019.

NEVES, M. Transconstitucionalismo. São Paulo: Martins Fontes, 2009.

NONET, P.; SELZNICK, P. Direito e sociedade. Rio de Janeiro: Revan, 2010.

ROCHA, L. S.; COSTA, B. L. C. Constitucionalismo social: Constituição na globalização. Curitiba: Appris, 2018.

SCHMITT, C. O guardião da Constituição. Tradução Geraldo de Carvalho. Belo Horizonte: Del Rey, 2007.

TEUBNER, G. A bukowina global sobre a emergência de um pluralismo jurídico internacional. Impulso: Revista de Ciências Sociais e Humanas, v. 14, p. 9-31, 2003.

TEUBNER, G. El derecho como sistema autopoiético de la sociedad global. Lima: ARA Editores, 2005a.

TEUBNER, G. Direito regulatório: crônica de uma morte anunciada. In: TEUBNER, G. Direito, sistema e policontexturalidade. Campinas: Unicamp, 2005b.

TEUBNER, G. Direito, sistema e policontexturalidade. Piracicaba: Unimep, 2005c.

TEUBNER, G. Constitucionalismo social: nove variações sobre o tema proposto por David Sciulli. In: CAMPOS, R.; BARBOSA, S. (org.). Teorias contemporâneas do direito: o direito e as incertezas normativas. Curitiba: Juruá, 2016a. p. 129-156.

TEUBNER, G. Fragmentos constitucionais: constitucionalismo social na globalização. São Paulo: Saraiva, 2016b. 
THORNHILL, C. A Sociology of Constitutions: Constitutions and state legitimacy in historical-sociological perspective. New York: Cambridge University Press, 2011.

THORNHILL, C. A Sociology of Transnational Constitutions: Social Foundations of the Post-National Legal Structure. New York: Cambridge University Press, 2016.

TUSHNET, M. The inevitable globalization of constitutional law. Virginia Journal of International Law, v. 49, n. 4, p. 985-1006, 2009. 